
\title{
$\begin{array}{ll}\text { Research Square } & \begin{array}{l}\text { They should not be considered conclusive, used to inform clinical practice, } \\ \text { or referenced by the media as validated information. }\end{array}\end{array}$
}

\section{Association of lodine-Related Knowledge, Attitudes, and Behaviours with Urinary lodine Excretion in Pregnant Women with Mild lodine Deficiency}

\author{
Zhengyuan Wang \\ Shanghai CDC \\ Yiwen Wu \\ Shanghai CDC \\ Zehuan Shi \\ Shanghai CDC \\ Jun Song \\ Shanghai CDC \\ Guoquan Wang \\ Shanghai CDC \\ Qi Song \\ Shanghai CDC \\ Wei Jin \\ Shanghai CDC \\ Xueying Cui \\ Shanghai CDC \\ Chunfeng Wu \\ Shanghai CDC \\ Jiajie Zang \\ Shanghai CDC \\ Changyi Guo ( 464315924@qq.com ) \\ shanghai cdc
}

Research

Keywords: Salt iodine concentration, Urinary iodine concentration, Pregnant women, Mild iodine deficiency

Posted Date: July 23rd, 2020

DOI: https://doi.org/10.21203/rs.3.rs-44718/v1

License: (a) (7) This work is licensed under a Creative Commons Attribution 4.0 International License. Read Full License

Version of Record: A version of this preprint was published at Journal of Human Nutrition and Dietetics on November 18th, 2020. See the published version at https://doi.org/10.1111/jhn.12837. 


\section{Abstract}

Background: China's universal salt-iodization program has all but eliminated iodine deficiency disorders. Concern has shifted to mild iodine deficiency. Our study examined factors with the potential to predict mild iodine deficiency in pregnant women.

Methods: A total of 2400 pregnant women were enrolled using a multistage, stratified, random-sampling method. Data were collected through face-to-face interviews, a standardized questionnaire, an iodine-related knowledge questionnaire, urine samples, and household cooking salt samples.

Results: The median urinary iodine concentration (MUIC) was $148.0 \mu \mathrm{g} / \mathrm{L}$ for all participants, and $155.0 \mu \mathrm{g} / \mathrm{L}, 151.0 \mu \mathrm{g} / \mathrm{L}$, and $139.6 \mu \mathrm{g} / \mathrm{L}$ in the first, second, and third trimesters, respectively. The third trimester's MUIC was significantly lower than that of the first trimester, and the usage rates of iodized salt and qualified-iodized salt were $71.5 \%$ and $59.4 \%$, respectively. lodine-related knowledge was significantly different between the high and low UIC groups. Participants' MUIC increased significantly with increases in iodine-related knowledge. The third trimester was a significant risk factor for high UIC, whereas abundant iodine-related knowledge, study the dietary knowledge urgently, and consumption of iodine-rich food within 48 hours of a urine iodine test were significant protective factors for high UIC $(P<0.05)$.

Conclusions: lodine levels are adequate among pregnant women in Shanghai during the first and second trimesters, but insufficient in the third trimester. The use of iodized cooking salt does not determine the iodine status of pregnant women. Abundant iodine-related knowledge is important for pregnant women in the third trimester to maintain adequate urinary iodine.

\section{Introduction}

lodine is a trace element that is essential for thyroid hormone synthesis, which is required for infants' physical growth and mental development [1, 2[. lodine deficiency leads to a series of adverse results, including endemic goitre and poor physical growth, collectively known as iodine deficiency disorders (IDDs). Severe iodine deficiency in pregnancy is well known to result in adverse childhood outcomes, such as cretinism and mental retardation [3]. In past decades, IDDs have become the most prevalent micronutrient-related diseases worldwide; approximately 30\% (1.9 billion) of the global population (especially children and pregnant women) suffer from different levels of iodine deficiency [4]. In 1990, the UN World Summit for Children established the global elimination of iodine deficiency as a priority goal [5]. Universal salt iodization (USI) was introduced to iodine-deficient regions; thus, areas with severe deficiencies have become uncommon and the concern has shifted toward mild to moderate iodine deficiency [6]. Studies suggest that even mild iodine deficiency during pregnancy may negatively affect the verbal intelligence quotient and educational level of offspring [7-9].

Despite the great progress achieved in recent years, mild iodine deficiency is still common among pregnant women. The median urinary iodine concentration (MUIC) of pregnant participants in the US National Health and Nutrition Examination Survey 2005-2010 was $129 \mu \mathrm{g} / \mathrm{L}$, indicating insufficient iodine status [10]. In 2019, the MUIC of pregnant women in Britain during their three trimesters were 94,117 , and $90 \mu \mathrm{g} / \mathrm{L}$, respectively [11]. In pregnant populations, iodine sufficiency is defined as a MUIC of 150-249 $\mathrm{g} / \mathrm{L}$, which corresponds to an iodine intake of $250 \mu \mathrm{g} / \mathrm{day}$ recommended by the World Health Organization (WHO) [12].

Although Shanghai is a developed coastal city, it is also an iodine deficiency area with low iodine concentrations in the drinking water (12.8 $\mu \mathrm{g} / \mathrm{L})$, according to the latest Chinese standard implemented in 2020 [13, 14]. Shanghai has followed the national compulsive universal salt iodization (USI) policy since 1996; the city began monitoring the iodine status of children 8-10-year old in 1995 and of pregnant women in 2009. According to the monitoring data, the iodine status of Shanghai's 8-10-year-old children has been adequate since 2005, but the MUIC of pregnant women has indicated mild iodine deficiency, with a level of only $135.9 \mu \mathrm{g} / \mathrm{L}$ in $2009,139.8 \mu \mathrm{g} / \mathrm{L}$ in 2012 , and $126.5 \mu \mathrm{g} / \mathrm{L}$ in 2015 [14-16]. Furthermore, monitoring in Shanghai has revealed that more and more families choose non-iodized salt as their cooking salt, and the rate of households with iodized salt dropped from $94.6 \%$ in 1999 to $76.5 \%$ in 2017 [16]. Hence, iodine nutrient levels in pregnant women are a concern.

Since January 1,2017, China's salt industry has undergone reforms, allowing business to be conducted across regions, which has increased problems with its management and supervision. Sales of non-iodized salt have shifted from being sold only through government-qualified channels to being purchased on the Internet and other venues. Hence, a growing number of households are likely to opt for non-iodized salt, thereby reducing the consumption rate of iodized salt. Given these developments, we conducted this study to assess systematically, the iodine status of pregnant women in Shanghai during 2019 , and to explore factors with the potential to predict their iodine status.

\section{Materials And Methods Population and study design}

The data were retrieved from the results of Shanghai's annual IDD surveillance, from March to June 2019. The target population was pregnant women with at least twelve continuous months of residency in Shanghai. A multi-stage, stratified random sampling method was conducted in 16 districts of Shanghai. The formula for calculating stratified random sampling sample size which was $n=z^{2 \star} S^{2 \star} d e f f / d^{2}$ was used to calculate the sample size required for analysis. According to the results of pregnant women iodine nutrition survey in 2009 in Shanghai, $S=15 \mu \mathrm{g} / \mathrm{L}, \mathrm{d}=15 \mu \mathrm{g} / \mathrm{L} * 0.05=0.75 \mu \mathrm{g} / \mathrm{L}$. We defined the two-sided significance level $a=0.05,1-\beta=0.8, z_{\alpha / 2}=1.96$. The deff value of stratified random sampling was 1 . At least 1537 pregnant women were needed for analysis. Each district was divided into five sections, a street was randomly selected from each section, and 30 pregnant women were selected from each of the five selected streets. The different gestational weeks of the women were evenly distributed. 


\section{Questionnaire Survey}

All participants were required to complete a standardized questionnaire, which included information on their demographics, salt consumption, and iodinerelated knowledge through face-to-face interviews with trained interviewers. Participants' iodine-related knowledge, attitudes and behaviours was measured using a questionnaire with a total possible score of ten points, based on respondents' ratings of the questions. The questionnaire was adopted after five experts reviewed its clarity and comprehension and agreed on all the items used in the questionnaire. The reliability coefficient of the questionnaire was 0.87 , which was considered acceptable. lodine-related knowledge was expressed as each participant's total score on the questionnaire. All data were reviewed by the local district CDC project team, and the Shanghai CDC project team reviewed at least $5 \%$ of the data.

\section{Data collection and analyses of household cooking salt and urine samples}

More than $50 \mathrm{~g}$ of household cooking salt from each subject were collected during the household assessment. And $5 \mathrm{ml}$ of fasting urine All urine samples were temporarily stored in a refrigerator at $4{ }^{\circ} \mathrm{C}$, then stored in a freezer at $-20{ }^{\circ} \mathrm{C}$ for 12 hours, and finally transported to the testing unit within two weeks. All cooking salt samples were stored at room temperature and transported to the laboratory within one week.

The household cooking salt iodine concentration (SIC) and urinary iodine concentration (UIC) were measured through titration and acid digestion [17, 18], respectively, at the Central Laboratory of Shanghai's Municipal CDC and the 16 district CDCs in Shanghai. The internal quality control of the samples for the analyses of the SIC and UIC were provided by China's National lodine Deficiency Disorders Reference Laboratory of the CDC.

\section{Definitions And Classifications Of Relevant Indicators}

Cooking SIC was classified into two types based on cooking SIC standards in Shanghai: non-iodized salt (SIC $<5.0 \mathrm{mg} / \mathrm{kg}$ ) and iodized salt (SIC $\geq 5.0 \mathrm{mg} / \mathrm{kg}$ ) which included low-iodized salt $(5.0 \mathrm{mg} / \mathrm{kg} \leq \mathrm{SIC}<21.0 \mathrm{mg} / \mathrm{kg})$ and qualified-iodized salt (SIC $\geq 21.0 \mathrm{mg} / \mathrm{kg})$.

The usage rate of iodized salt was equal to the percentage of salt with an iodine level $\geq 5.0 \mathrm{mg} / \mathrm{kg}$ in all samples.

The usage rate of qualified-iodized salt was equal to the percentage of salt with an iodine content $\geq 21.0 \mathrm{mg} / \mathrm{kg}$ in all samples.

The 'abundant knowledge' group consisted of participants who scored 8-10 points on the iodine-related knowledge questionnaire. The 'general knowledge' group were those who scored 6-7 points on the iodine-related knowledge questionnaire. The 'lack of knowledge' group were those who scored $\leq 5$ points on the iodine-related knowledge questionnaire.

Former smokers were participants who smoked cigarettes in the past, excluding those who took a few tentative puffs. Former drinkers were those who usually drank alcoholic beverages during non-gestational periods, excluding those who sipped some wine.

The nutritional iodine status of the pregnant women was determined using the recommended criteria of the WHO/United Nations Children's Fund (UNICEF)/International Council for the Control of lodine Deficiency Disorders (ICCIDD). Insufficient iodine intake was defined as MUIC < $150 \mu g / L$; adequate iodine intake as MUIC $150-249 \mu \mathrm{g} / \mathrm{L}$; iodine intake above the requirement as MUIC $250-499 \mu \mathrm{g} / \mathrm{L}$; and excessive iodine intake as MUIC $\geq 500 \mu \mathrm{g} / \mathrm{L}$ [12].

Because of the high within-person variability of a single spot urine, the WHO programme guide limited the use and interpretation based on single spot urine per participant to population median of a sufficiently large group (in general, >30) [12]. In our study, the sampling error (95\% confidence interval (Cl) of the MUIC) was considered and calculated using bootstrapping. Pregnant women are divided into 48 units according to the district and trimester. When the upper cut-off level of the $95 \% \mathrm{Cl}$ the MUIC in a unit was higher than $150 \mu \mathrm{g} / \mathrm{L}$, the iodine status was considered optimal for all pregnant women in this unit, these participants were categorized as high UIC and the others were low UIC.

The definition of iodine-rich foods, which included kelp, laver, seaweed, and shrimp, was based on the eating habits of Shanghai residents and the food composition tables published in the China Health and Nutrition Survey ${ }^{(19)}$.

\section{Statistical analysis}

Statistical analyses were conducted with Excel (2010 Edition, Microsoft, China) and SPSS (version 21.0, China). Frequency count data are expressed as number and percentage (\%), normally distributed data are expressed as mean \pm standard deviation (SD), and non-parametric data are expressed as the median (25th percentile, 75th percentile). One-way analysis of variance (ANOVA) was used to compare multiple groups. In pairwise comparisons, homogeneity of variance was tested using the least significant difference (LSD) test, and heterogeneity of variance was assessed using Tamhane's T2 test. The Kruskal-Wallis one-way ANOVA was used to compare the non-parametric data of multiple groups. Binary logistic regression analyses were used to explore factors with the potential to predict low UIC. A P-value below 0.05 was considered to be statistically significant.

\section{Results}

\section{Characteristics of the participants by trimester}

A total of 2400 eligible participants were included in the study. The MUIC was $148.0 \mu \mathrm{g} / \mathrm{L}$ for all participants, and $155.0 \mu \mathrm{g} / \mathrm{L}, 151.0 \mu \mathrm{g} / \mathrm{L}$, and $139.6 \mu \mathrm{g} / \mathrm{L}$ for women in the first, second, and third trimesters, respectively. A significant difference was found in the MUICs at different gestational weeks (P = 0.027). Pairwise comparisons found a significant difference only between the first and third trimesters, with a higher MUIC during the first trimester; the adjusted P- 
value was 0.022 . A total of 1715 households used iodized salt as cooking salt, of which 1426 used qualified cooking salt. The usage rates of the iodized salt and qualified-iodized salt were $71.5 \%$ and $59.4 \%$, respectively. The mean iodine content in the iodized salt was $23.9 \mathrm{mg} / \mathrm{kg}$.

Age, educational status, occupational status, family income during the past year, thyroid disease history, drinking and smoking habits, and iodine-related knowledge were analysed (Table 1). Comparisons of participants' characteristics by pregnancy trimester revealed a significant difference in educational status among the women in the different trimesters $(P=0.005)$. No significant differences in the other characteristics were found. 
Table 1

Characteristics of the study participants stratified by gestational weeks and UIC

\begin{tabular}{|c|c|c|c|c|c|c|c|c|c|c|c|c|}
\hline & \multicolumn{3}{|c|}{ First trimester } & \multicolumn{3}{|c|}{ Second trimester } & \multicolumn{3}{|c|}{ Third trimester } & \multicolumn{3}{|l|}{ Pooled } \\
\hline & $\begin{array}{l}\text { Low } \\
\text { UIC }\end{array}$ & $\begin{array}{l}\text { High } \\
\text { UIC }\end{array}$ & Total & $\begin{array}{l}\text { Low } \\
\text { UIC }\end{array}$ & $\begin{array}{l}\text { High } \\
\text { UIC }\end{array}$ & Total & $\begin{array}{l}\text { Low } \\
\text { UIC }\end{array}$ & $\begin{array}{l}\text { High } \\
\text { UIC }\end{array}$ & Total & $\begin{array}{l}\text { Low } \\
\text { UIC }\end{array}$ & $\begin{array}{l}\text { High } \\
\text { UIC }\end{array}$ & $\mathrm{T}_{\mathrm{r}}$ \\
\hline $\mathbf{N}$ & 344 & 468 & 802 & 348 & 453 & 801 & 368 & 429 & 797 & 1050 & 1350 & 2 \\
\hline $\begin{array}{l}\text { UIC, } \mu \mathrm{g} / \mathrm{L} \\
\text { (Median } \\
\text { [P25, } \\
\text { P75]) }\end{array}$ & I & / & $155.0(91.0,257.3)$ & / & / & $151.0(87.1,242.0)$ & / & / & $139.6(80.0,234.0)$ & / & / & 1 . \\
\hline $\begin{array}{l}\text { SIC in } \\
\text { iodized } \\
\text { salt, } \\
\mathrm{mg} / \mathrm{kg} \\
\text { (Mean } \pm \\
\text { SD) }\end{array}$ & $\begin{array}{l}24.3 \pm \\
4.5\end{array}$ & $\begin{array}{l}24.1 \\
\pm 5.3\end{array}$ & $24.2 \pm 5.0$ & $\begin{array}{l}23.8 \\
\pm 4.9\end{array}$ & $\begin{array}{l}23.6 \\
\pm 4.8\end{array}$ & $23.7 \pm 4.9$ & $\begin{array}{l}23.9 \\
\pm 4.4\end{array}$ & $\begin{array}{l}23.9 \\
\pm 4.1\end{array}$ & $24.0 \pm 4.3$ & $\begin{array}{l}24.0 \\
\pm 4.6\end{array}$ & $\begin{array}{l}23.9 \\
\pm 4.8\end{array}$ & $2:$ \\
\hline $\begin{array}{l}\text { Usage rate } \\
\text { of iodized } \\
\text { salt (\%) }\end{array}$ & $68.2 \%$ & $74.2 \%$ & $71.3 \%$ & $71.1 \%$ & $74.4 \%$ & $72.8 \%$ & $68.5 \%$ & $72.3 \%$ & $70.3 \%$ & $69.3 \%$ & $73.7 \%$ & 7 \\
\hline $\begin{array}{l}\text { Usage rate } \\
\text { of } \\
\text { approved } \\
\text { iodized } \\
\text { salt (\%) }\end{array}$ & $57.0 \%$ & $61.7 \%$ & $59.5 \%$ & $59.0 \%$ & $60.0 \%$ & $59.6 \%$ & $57.6 \%$ & $61.1 \%$ & $59.2 \%$ & $57.9 \%$ & $61.0 \%$ & 5 \\
\hline $\begin{array}{l}\text { Age } \geq \\
35 \text { years } \\
(\%)\end{array}$ & $14.3 \%$ & $12.2 \%$ & $13.2 \%$ & $13.6 \%$ & $11.9 \%$ & $12.7 \%$ & $9.3 \%$ & $10.9 \%$ & $10.0 \%$ & $12.3 \%$ & $11.7 \%$ & 1: \\
\hline $\begin{array}{l}\text { Ate iodine- } \\
\text { rich food } \\
\text { in past } \\
24-48 \\
\text { hours }(\%)\end{array}$ & $56.7 \%$ & $43.3 \%$ & $39.8 \%$ & $35.7 \%$ & $37.0 \%$ & $36.3 \%$ & $33.1 \%$ & $38.0 \%$ & $35.4 \%$ & $34.8 \%$ & $39.5 \%$ & 3 \\
\hline $\begin{array}{l}\text { Study the } \\
\text { dietary } \\
\text { knowledge } \\
\text { urgently } \\
\text { (\%) }\end{array}$ & $78.6 \%$ & $85.9 \%$ & $82.4 \%$ & $78.9 \%$ & $82.1 \%$ & $80.5 \%$ & $80.2 \%$ & $86.4 \%$ & $83.1 \%$ & $79.3 \%$ & $84.8 \%$ & 8: \\
\hline $\begin{array}{l}\text { Former } \\
\text { smoker } \\
(\%)\end{array}$ & $2.6 \%$ & $2.6 \%$ & $2.6 \%$ & $2.0 \%$ & $2.5 \%$ & $2.2 \%$ & $1.4 \%$ & $1.4 \%$ & $1.4 \%$ & $2.0 \%$ & $2.2 \%$ & 2. \\
\hline $\begin{array}{l}\text { Former } \\
\text { drinker (\%) }\end{array}$ & $6.0 \%$ & $8.4 \%$ & $7.2 \%$ & $9.0 \%$ & $8.4 \%$ & $8.7 \%$ & $7.0 \%$ & $5.7 \%$ & $6.4 \%$ & $7.3 \%$ & $7.3 \%$ & 7. \\
\hline \multicolumn{13}{|c|}{ Occupational status (\%) } \\
\hline Physical & $23.4 \%)$ & $29.4 \%$ & $26.6 \%$ & $26.9 \%$ & $24.3 \%$ & $25.6 \%$ & $27.5 \%$ & $32.3 \%$ & $29.7 \%$ & $26.0 \%$ & $28.6 \%$ & 2 \\
\hline Mental & $76.6 \%$ & $70.6 \%$ & $73.4 \%$ & $73.1 \%$ & $75.7 \%$ & $74.4 \%$ & $72.5 \%$ & $67.7 \%$ & $70.3 \%$ & $74.0 \%$ & $71.4 \%$ & 7: \\
\hline \multicolumn{13}{|c|}{ Educational status (\%) } \\
\hline$\leq 9$ years & $9.6 \%$ & $11.7 \%$ & $10.7 \%$ & $17.3 \%$ & $15.9 \%$ & $16.7 \%$ & $16.3 \%$ & $12.2 \%$ & $14.6 \%$ & $14.5 \%$ & $13.3 \%$ & 1 . \\
\hline $\begin{array}{l}\text { Senior } \\
\text { high } \\
\text { school } \\
\text { and } \\
\text { college }\end{array}$ & $37.0 \%$ & $39.7 \%$ & $38.4 \%$ & $37.7 \%$ & $40.7 \%$ & $39.4 \%$ & $35.9 \%$ & $37.2 \%$ & $36.7 \%$ & $37.0 \%$ & $39.6 \%$ & $3 i$ \\
\hline $\begin{array}{l}\text { Bachelor 's } \\
\text { degree } \\
\text { and above }\end{array}$ & $52.6 \%$ & $48.6 \%$ & $50.5 \%$ & $44.7 \%$ & $42.9 \%$ & $43.9 \%$ & $47.1 \%$ & $50.3 \%$ & $48.7 \%$ & $48.5 \%$ & $47.1 \%$ & 4 \\
\hline \multicolumn{13}{|c|}{ Family income in the past year, YUAN (\%) } \\
\hline$<100000$ & $12.8 \%$ & $14.8 \%$ & $13.8 \%$ & $17.3 \%$ & $10.9 \%$ & $14.3 \%$ & $12.6 \%$ & $12.0 \%$ & $12.3 \%$ & $14.2 \%$ & $12.6 \%$ & $1:$ \\
\hline $\begin{array}{l}100 \\
000 / 200 \\
000\end{array}$ & $32.2 \%$ & $35.2 \%$ & $33.9 \%$ & $35.7 \%$ & $41.3 \%$ & $38.6 \%$ & $39.4 \%$ & $40.0 \%$ & $39.6 \%$ & $35.8 \%$ & $38.7 \%$ & 3 \\
\hline$\geq 200000$ & $55.0 \%$ & $49.3 \%$ & $52.3 \%$ & $46.5 \%$ & $47.8 \%$ & $47.1 \%$ & $48.0 \%$ & $48.0 \%$ & $48.1 \%$ & $49.6 \%$ & $48.3 \%$ & $4^{\prime}$ \\
\hline
\end{tabular}

P25, 25th percentile; P75, 75th percentile; UIC, urinary iodine concentration; SIC, salt iodine concentration 


\begin{tabular}{|c|c|c|c|c|c|c|c|c|c|c|c|c|}
\hline & \multicolumn{3}{|c|}{ First trimester } & \multicolumn{3}{|c|}{ Second trimester } & \multicolumn{3}{|c|}{ Third trimester } & \multicolumn{3}{|c|}{ Pooled } \\
\hline \multicolumn{13}{|c|}{ lodine-related knowledge (\%) } \\
\hline $\begin{array}{l}\text { Lack of } \\
\text { knowledge }\end{array}$ & $36.2 \%$ & $25.8 \%$ & $30.8 \%$ & $33.7 \%$ & $30.5 \%$ & $32.1 \%$ & $31.9 \%$ & $23.6 \%$ & $28.1 \%$ & $33.9 \%$ & $26.7 \%$ & 31 \\
\hline $\begin{array}{l}\text { General } \\
\text { knowledge }\end{array}$ & $32.3 \%$ & $32.8 \%$ & $32.5 \%$ & $32.2 \%$ & $32.5 \%$ & $32.3 \%$ & $33.8 \%$ & $32.1 \%$ & $33.0 \%$ & $32.8 \%$ & $32.5 \%$ & 3: \\
\hline $\begin{array}{l}\text { Abundant } \\
\text { knowledge }\end{array}$ & $31.5 \%$ & $41.4 \%$ & $36.7 \%$ & $34.2 \%$ & $37.0 \%$ & $35.6 \%$ & $34.3 \%$ & $44.3 \%$ & $38.9 \%$ & $33.4 \%$ & $40.8 \%$ & 3 \\
\hline \multicolumn{13}{|c|}{$\begin{array}{l}\text { Thyroid disease } \\
\text { history (\%) }\end{array}$} \\
\hline $\begin{array}{l}\text { No thyroid } \\
\text { disease } \\
\text { history }\end{array}$ & $87.8 \%$ & $89.5 \%$ & $88.7 \%$ & $88.9 \%$ & $87.1 \%$ & $88.0 \%$ & $87.9 \%$ & $90.5 \%$ & $89.1 \%$ & $88.2 \%$ & $89.0 \%$ & $8 i$ \\
\hline $\begin{array}{l}\text { Had } \\
\text { thyroid } \\
\text { disease }\end{array}$ & $12.2 \%$ & $10.5 \%$ & $11.3 \%$ & $11.1 \%$ & $12.9 \%$ & $12.0 \%$ & $12.1 \%$ & $9.5 \%$ & $10.9 \%$ & $11.8 \%$ & $11.0 \%$ & 1 . \\
\hline
\end{tabular}

P25, 25th percentile; $\mathrm{P} 75$, 75th percentile; UIC, urinary iodine concentration; SIC, salt iodine concentration

The women were divided into two groups, high UIC and low UIC. lodine-related knowledge, usage rates of iodized salt, consumption of iodine-rich food within 48 hours of having an on-the spot iodine urine test, and study the dietary knowledge urgently were significantly between the two UIC groups $(P<0.05)$.

\section{The distributions of UICs and MUICs among women with different knowledge scores}

The percentages of UICs ranged between 150 and $250 \mu \mathrm{g} / \mathrm{L}$ were $26.1 \%, 25.8 \%, 23.1 \%$, for participants in the first, second, and third trimesters, respectively, and $25.0 \%$ for the pooled results (Fig. 1).

The MUICs of the participants, which varied by their iodine-related knowledge scores, were $133.5 \mu \mathrm{g} / \mathrm{L}$ in the 'lack of knowledge' group, $146.0 \mu \mathrm{g} / \mathrm{L}$ in the 'general knowledge' group, and $164.0 \mu \mathrm{g} / \mathrm{L}$ in the group with 'abundant knowledge' (Fig. 2). A significant difference was found between the UICs of the three groups and the pooled results $(\mathrm{P}<0.001)$. The adjusted $\mathrm{P}$-values for the pairwise comparisons were 0.046 between the 'lack of knowledge' and 'general knowledge' groups, $<0.001$ between the 'lack of knowledge' and 'abundant knowledge' groups, and 0.035 between the 'general knowledge' and 'abundant knowledge' groups. The results showed that the MUIC increased with increases in knowledge scores.

As trimester was found to be a predictor of UIC, we controlled for the impact of trimester on UIC by comparing the groups with different scores in the same trimester. The differences in the MUIC between the groups with different scores in the same trimester were compared using the Kruskal-Wallis test, which found significant differences between the groups with different knowledge scores in the first $(P<0.001)$ and third $(P=0.012)$ trimesters. The pairwise comparisons of the groups with different scores in the first and third trimesters showed a significant difference only between the 'lack of knowledge' $(P<$ 0.001) and the 'abundant knowledge' groups ( $P=0.009)$.

\section{Analysis of the factors associated with UIC}

Based on the standards of international organizations (WHO/UNICEF/ICCIDD), patients were divided into two groups, high UIC and low UIC. UIC was used as the dependent variable, and the variables that were significant in the univariate analysis were used as the independent variables in the binary logistic regression (Table 2). Variables with multiple classifications were treated as dummy variables. The results showed four variables in the model: iodine-related knowledge, consumption of iodine-rich food within 48 hours of an iodine urine test, study the dietary knowledge urgently, and the third trimester. Compared to the first trimester, the third trimester was found to be a risk factor for high UIC $(P=0.016)$. Abundant iodine-related knowledge versus lack of knowledge $(P<$ 0.001), eating iodine-rich foods within 48 hours of an iodine urine test versus not eating iodine-rich foods $(P=0.046)$, and study the dietary knowledge urgently versus no study of dietary information $(P=0.002)$ served as protective factors for high UIC. 
Table 2

Potential factors associated with urinary iodine concentration

\begin{tabular}{|c|c|c|c|c|}
\hline & $\beta$ & Coefficient. & $95 \% \mathrm{Cl}$ & $\mathbf{P}$ \\
\hline \multicolumn{5}{|l|}{ Trimester } \\
\hline First trimester & \multicolumn{4}{|c|}{ Reference } \\
\hline Second trimester & -0.061 & 1.063 & $0.872 / 1.296$ & 0.546 \\
\hline Third trimester & -0.245 & 1.278 & $1.048 / 1.559$ & 0.016 \\
\hline \multicolumn{5}{|l|}{ Thyroid disease history } \\
\hline No thyroid disease history & \multicolumn{4}{|c|}{ Reference } \\
\hline Had thyroid disease & -0.306 & / & / & 0.580 \\
\hline \multicolumn{5}{|l|}{ Age $\geq 35$ years } \\
\hline No & \multicolumn{4}{|c|}{ Reference } \\
\hline Yes & -0.140 & / & / & 0.708 \\
\hline \multicolumn{5}{|l|}{ Occupational status } \\
\hline Mental & \multicolumn{4}{|c|}{ Reference } \\
\hline Physical & -1.575 & / & / & 0.209 \\
\hline \multicolumn{5}{|l|}{ Educational status } \\
\hline$\leq 9$ years & \multicolumn{4}{|c|}{ Reference } \\
\hline Senior high school and college & -1.021 & / & / & 0.312 \\
\hline Bachelor's degree and above & -0.926 & / & / & 0.336 \\
\hline \multicolumn{5}{|c|}{ Family income in the past year, YUAN } \\
\hline$<100000$ & \multicolumn{4}{|c|}{ Reference } \\
\hline $100000 / 200000$ & -2.887 & / & / & 0.089 \\
\hline$\geq 200000$ & -1.023 & / & / & 0.312 \\
\hline \multicolumn{5}{|l|}{ Salt groups } \\
\hline Non-iodized salt & \multicolumn{4}{|c|}{ Reference } \\
\hline Qualified-iodized salt & -1.569 & / & / & 0.210 \\
\hline Low-iodized salt & -1.245 & / & / & 0.265 \\
\hline \multicolumn{5}{|l|}{ lodine-related knowledge scores } \\
\hline Lack of knowledge & \multicolumn{4}{|c|}{ Reference } \\
\hline General knowledge & 0.179 & 0.836 & $0.681 / 1.027$ & 0.088 \\
\hline Abundant knowledge & 0.375 & 0.687 & $0.562 / 0.84$ & 0.000 \\
\hline \multicolumn{5}{|c|}{ Ate iodine-rich food in the past $24-48$ hours } \\
\hline No & \multicolumn{4}{|c|}{ Reference } \\
\hline Yes & 0.171 & 0.843 & $0.712 / 0.997$ & 0.046 \\
\hline \multicolumn{5}{|c|}{ Study the dietary knowledge urgently } \\
\hline No & \multicolumn{4}{|c|}{ Reference } \\
\hline Yes & 0.333 & 0.717 & $0.579 / 0.888$ & 0.002 \\
\hline \multicolumn{5}{|l|}{ Former smoker } \\
\hline No & \multicolumn{4}{|c|}{ Reference } \\
\hline Yes & -0.067 & / & / & 0.796 \\
\hline \multicolumn{5}{|l|}{ Former drinker } \\
\hline No & \multicolumn{4}{|c|}{ Reference } \\
\hline Yes & -0.064 & / & / & 0.800 \\
\hline
\end{tabular}




\section{Discussion}

It is particularly important for pregnant women to have adequate iodine intake, which is not only related to pregnancy outcomes, but also to the mental and physical development of the foetus [20]. Recent, continuous reports have documented iodine deficiency in pregnant women in China [21-23]. The Chinese CDC conducted a cross-sectional study on the relationship between thyroid disease and different levels of iodine intake, which indicated low coverage of iodized salt in the coastal cities of China and low iodine concentrations in the environment; the incidence rate of thyroid dysfunction and the UICs showed a Ushaped curve [22]. All these findings suggest that the iodine status of pregnant women is worthy of attention, especially in regions where both iodine in the drinking water and the usage of iodized salt are low.

Although Shanghai is located on the coast, it is classified as an iodine-deficient region because of its low water concentration of iodine. In 2009, a crosssectional survey of 7904 participants in all districts of Shanghai found that the median iodine concentration in the drinking water was only $12.8 \mu \mathrm{g} / \mathrm{L}$, which is well below the standard cut-off point of $40 \mu \mathrm{g} / \mathrm{L}$ for iodine-deficient areas. The survey also found that iodized salt was the main source of dietary iodine in Shanghai, accounting for $63.5 \%$ [14].

Our study found that the UIC of pregnant women in Shanghai in 2019 was $148.0 \mu \mathrm{g} / \mathrm{L}$, indicating mild iodine deficiency $(100-149 \mu \mathrm{g} / \mathrm{L})$, according to the WHO recommendations [12]. The results are similar to those of previous Shanghai monitoring reports [14, 15]. According to our findings, trimesters affect the MUIC of pregnant women. The MUIC of the pregnant women in the third trimester $(139.6 \mu \mathrm{g} / \mathrm{L})$ was much lower than that of first trimester $(155.0 \mu \mathrm{g} / \mathrm{L})$. Moreover, a 2018 monitoring study in the Zhejiang province of China, which included 8651 pregnant women, found that trimester was significantly associated with low UIC, with the lowest concentration recorded in the third trimester and the highest in the first trimester [24]. This result is consistent with the results of a study of 2607 pregnant women in Chongqing, China, an iodine-sufficient area, which reported that women in the first trimester had a significantly higher MUICC $(189.7 \mu \mathrm{g} / \mathrm{L})$ than those in third trimester [163.0 $\mu \mathrm{g} / \mathrm{L})$ [25]. Similarly, a cross-sectional study conducted in Australia found women in the third trimester had a significantly lower MUIC than women in the first trimester (119 vs. $161 \mu \mathrm{g} / \mathrm{L}$ ) [26]. This finding may be related to the increasing thyroid hormone requirements of the foetus. Before 20 weeks of gestation, the foetal thyroid is not sufficiently mature to produce thyroid hormones independently. Therefore, during this period, the foetus depends entirely on the maternal thyroid hormones and iodine supply [27]. After the foetal thyroid matures, thyroid hormone synthesis increases, relying on iodine from the mother [28], which may increase the iodine requirements of pregnant women in the third trimester. Additional interventions, such as encouraging the intake of iodine-rich foods or iodine supplements are important recommendations for pregnant women in the third trimester.

Our study found that iodine-related dietary knowledge plays a vital role in the UIC of pregnant women, as shown in the univariate analysis and the binary logistic regression. The MUIC increased with higher knowledge scores. Although educational status was not significant in the multivariate analysis, the scores on iodine-related dietary knowledge suggest that iodine-related health education is likely to be crucial in preventing low UIC, and cannot be replaced by traditional health education. Furthermore, the 'study the dietary knowledge urgently' served as a protective factor for maintaining high UIC, thereby highlighting the importance of iodine-related health education. Nevertheless, $30.3 \%$ of the pregnant women in our study lacked iodine-related knowledge, which suggests that the iodine-related health education should be improved. A cross-sectional study on 804 pregnant women from 18 to 44 years of age in 2016 in Oslo, Norway, showed that $74 \%$ of them achieved low iodine-related knowledge scores [29]. A similar result was reported in a cross-sectional study of pregnant women living in Northern Ireland; only 20\% of the women were aware [30]. The results of a 2019 study of 2642 pregnant women in Zhejiang province, China, showed a linear upward trend in iodine-related knowledge scores with higher UICs [31]. According to a 2018 cross-sectional study of pregnant women in Istanbul, nutrition knowledge scores were significantly higher in the post-test (23.0) than the pre-test (16.0) after the respondents received nutrition education $(P<0.001)$ [32]. In the follow-up to the present study, we intend to strengthen the focus on nutrition-related knowledge and enhance participants' understanding of IDD in pregnant women.

Our study also found that the consumption rate of iodized salt was only $71.5 \%$, and the consumption rate of qualified iodized salt was only $59.4 \%$. Despite the low consumption rate of qualified iodized salt, our study found that $62.8 \%$ of pregnant women had consumed iodine-rich food 24 hours to 48 hours before submitting a sample for an on-the-spot urine iodine test, although iodine-rich foods were forbidden 24 hours before the test. This finding may reflect the dietary habits of eating iodine-rich foods in Shanghai. The multivariate analysis also showed that eating iodine-rich food in the $24-48$ hours before a urine iodine test, served as a protective factor for maintaining high UIC. Although iodized salt is a good source of dietary iodine, it is not the only one. Therefore, we should not focus excessive attention on its consumption rate; as long as pregnant women eat reasonable amounts of iodine-rich food, they can maintain their UIC at sufficient levels. Thus, it should be noted that in the case of low usage of iodized salt, iodine-related health education is vital for the pregnant population to maintain their UIC at sufficient levels.

\section{Conclusion}

In summary, participants' MUIC was $155.0 \mu \mathrm{g} / \mathrm{L}, 151.0 \mu \mathrm{g} / \mathrm{L}$, and $139.6 \mu \mathrm{g} / \mathrm{L}$ in first, second, and third trimesters, respectively, which suggests that pregnant women in the third trimester are at risk for mild iodine deficiency. The low consumption of qualified iodized salt among pregnant women is also a problem in Shanghai. Abundant iodine-related knowledge, study the dietary knowledge urgently, and eating iodine-rich food in the past 24 to 48 hours, had protective effects on the high UIC of pregnant women. Abundant iodine-related knowledge and positive attitudes and behaviours were associated with high urinary iodine excretion. Therefore, it is important to improve iodine-related health education for pregnant women in Shanghai. The health education should focus on third-trimester pregnant women and on guiding those who eat non-iodized salt to choose reasonable amounts of iodine-rich food.

\section{Declarations}

Acknowledgements 
We are grateful to the pregnant women who participated in this study and to the healthcare professionals from the CDC of the 16 districts in Shanghai.

\section{Authors' contributions}

All co-authors have contributed significantly to the planning of the analyses and interpretation of the data and have provided essential intellectual input. Analyzed the data, Z. W. and Y. W.; Investigation, W. J., X. C., Q. S. and Z. S.; Laboratory testing, J. S., G. W.; Project administration, C. G., Z. Z., C. W. and Z. Z.; Writing - original draft, Z. W., Y. W.

\section{Funding}

The study was financially supported by the National Nature Science Foundation of China (No. 81602851), the Excellent Young Talents of Health System in Shanghai (No. 2017YQ043) and Top Young Talents in Shanghai (No. 2020-8). They had no role in the design, analysis or writing of this article. This research received no specific grant from any funding agency, commercial or not-for-profit sectors.

\section{Availability of data and materials}

The datasets generated and analyzed during the current study are not publicly available but are available from the corresponding author on reasonable request.

\section{Ethics approval and consent to participate}

This study was conducted according to the guidelines laid down in the Declaration of Helsinki and all procedures involving human subjects were approved by the Shanghai Municipal Centre for Disease Control and Prevention (CDC). Written informed consent was obtained from all participants.

\section{Consent for publication}

Not applicable.

\section{Competing interests}

The authors have no conflicts of interest relevant to this study.

\section{Author details}

${ }^{1}$ Division of Health Risk Factors Monitoring and Control, Shanghai Municipal Center for Disease Control and Prevention, Shanghai 200336, China. ${ }^{2}$ Laboratory for the Determination of Biological Markers, Shanghai Municipal Center for Disease Control and Prevention, Shanghai 200336, China. ${ }^{3} \mathrm{General}$ Office, Shanghai Municipal Center for Disease Control and Prevention, Shanghai 200336, China.

\section{References}

1. Forhead AJ, Fowden AL. Thyroid hormones in fetal growth and prepartum maturation. J Endocrinol. 2004;221:R87-103.

2. Zimmermann MB. The role of iodine in human growth and development. Semin Cell Dev Biol. 2011;22:645-52.

3. Moreno-Reyes R, Glinoer D, Van Oyen H, et al. High prevalence of thyroid disorders in pregnant women in a mildly iodine-deficient country: a populationbased study. J Clin Endocrinol Metab. 2013;98:3694-701.

4. Zimmermann MB, Andersson M. Update on iodine status worldwide. Curr Opin Endocrinol Diabetes Obes. 2012;19:382-7.

5. WHO, UNICEF. (1994) World summit for children mid-decade goal: iodine deficiency disorders. Geneva: 1994, WHO.

6. Zimmermann MB. The adverse effects of mild-to-moderate iodine deficiency during pregnancy and childhood: a review. Thyroid. 2007;17:829-35.

7. Bath SC, Steer CD, Golding J, et al. Effect of inadequate iodine status in UK pregnant women on cognitive outcomes in their children: results from the Avon Longitudinal Study of Parents and Children (ALSPAC). Lancet. 2013;382:331-7.

8. Hynes KL, Otahal P, Hay I, et al. Mild iodine deficiency during pregnancy is associated with reduced educational outcomes in the offspring: 9-year followup of the gestational iodine cohort. J Clin Endocrinol Metab. 2013;98:1954-62.

9. Vermiglio F, Lo Presti VP, Moleti M, et al. Attention deficit and hyperactivity disorders in the offspring of mothers exposed to mild-moderate iodine deficiency: a possible novel iodine deficiency disorder in developed countries. J Clin Endocrinol Metab. 2004;89:6054-60.

10. Caldwell KL, Pan Y, Mortensen ME, et al. lodine status in pregnant women in the National Children's Study and in US women (15-44 years), National Health and Nutrition Examination Survey 2005-2010. Thyroid. 2013;23:927-37.

11. McMullan P, Hamill L, Doolan K, et al. lodine deficiency among pregnant women living in Northern Ireland. Clin Endocrinol. 2019;91:639-45.

12. WHO/UNICEF/ICCIDD Assessment of. iodine deficiency disorders and monitoring their elimination. 3rd. Geneva: World Health Organization; 2007.

13. Definition. and demarcation of iodine deficient areas and iodine adequate areas (WS/T 669-2020). National health commission of the People's Republic of China, Beijin.

14. Zou S, Wu F, Guo C, et al. lodine nutrition and the prevalence of thyroid disease after salt iodization: a cross-sectional survey in Shanghai, a coastal area in China. PLoS One. 2002;7:e40718. 
15. Wang Z, Liu P, Su X, et al. A comparison of iodine status in children and pregnant women after a policy change in the iodized salt standard in Shanghai, China. Biol Trace Elem Res. 2018;185:275-81.

16. Wang Z, Zang J, Shi Z, et al. lodine status of 8 to 10 years old children within 20 years following compulsory salt iodization policy in Shanghai, China. Nutr J. 2019;18:63.

17. Genaral test method in. salt industry-Determination of iodine (GB/T 13025.7-2012). National standardization administration of China, Beijin.

18. Determination of iodine in. urine - Part 1: As3+-Ce4 + catalytic spectrophotometry (WS/T 107.1-2016). Health and Family Planning Commission of China, Beijin.

19. Yang Y. China food Composition. Beijing: Peking University Medical Press; 2009.

20. Bath SC. The effect of iodine deficiency during pregnancy on child development. Proceedings of the Nutrition Society. Proc Nutr Soc 2019, 78, $150-160$.

21. Yang L, Li M, Liu X, et al. Evaluation of lodine Nutritional Status Among Pregnant Women in China. Thyroid. 2020;30:443-50.

22. Du Y, Gao Y, Meng F, et al. lodine deficiency and excess coexist in china and induce thyroid dysfunction and disease: a cross-sectional study. PLoS One. 2014;9:e111937.

23. $10.1007 / \mathrm{s} 12011-020-02135-6$

Zhou H, Lu Y, Pan B, et al. lodine Deficiency as Assessed by Neonatal TSH in a Sample of Mother-and-Newborn Pairs in Jiangsu Province, China. Biol Trace Elem Res2020, 1-6, doi: 10.1007/s12011-020-02135-6.

24. Wang Z, Xing M, Zhu W, et al. lodine deficiency in Zhejiang pregnant women in the context of universal salt iodization programme. Sci Rep. $2017 ; 8: 1-7$.

25. Yao N, Zhou C, Xie J, et al. A cross-sectional research of iodine status of pregnant women in Chongqing, south-west China. Public Health Nutr. 2020;23:769-75.

26. Hynes KL, Seal JA, Otahal P, et al. Women remain at risk of iodine deficiency during pregnancy: the importance of iodine supplementation before conception and throughout gestation. Nutrients. 2019;11:172.

27. Joshi K, Nair S, Khade C, et al. Early gestation screening of pregnant women for iodine deficiency disorders and iron deficiency in urban centre in Vadodara, Gujarat, India. J Dev Orig Health Dis. 2014;5:63-8.

28. Brown RS. Minireview: developmental regulation of thyrotropin receptor gene expression in the fetal and newborn thyroid. Endocrinology. 2004;145:405861.

29. Garnweidner-Holme L, Aakre I, Lilleengen AM, et al. Knowledge about iodine in pregnant and lactating women in the Oslo area. Norway Nutrients. 2017;9:493.

30. McMullan P, Hunter A, McCance D, et al. Knowledge about iodine requirements during pregnancy and breastfeeding among pregnant women living in Northern Ireland. BMC Nutr. 2019;5:24.

31. Wang X, Lou X, Mo Z, et al. Poor iodine knowledge, coastal region, and non-iodized salt consumption linked to low urinary iodine excretion in Zhejiang pregnant women. Nutrients. 2019;11:413.

32. Aktaç S, Sabuncular G, Kargin D, et al. Evaluation of Nutrition Knowledge of Pregnant Women before and after Nutrition Education according to Sociodemographic Characteristics. Ecol Food Nutr. 2018;57:441-55.

\section{Figures}

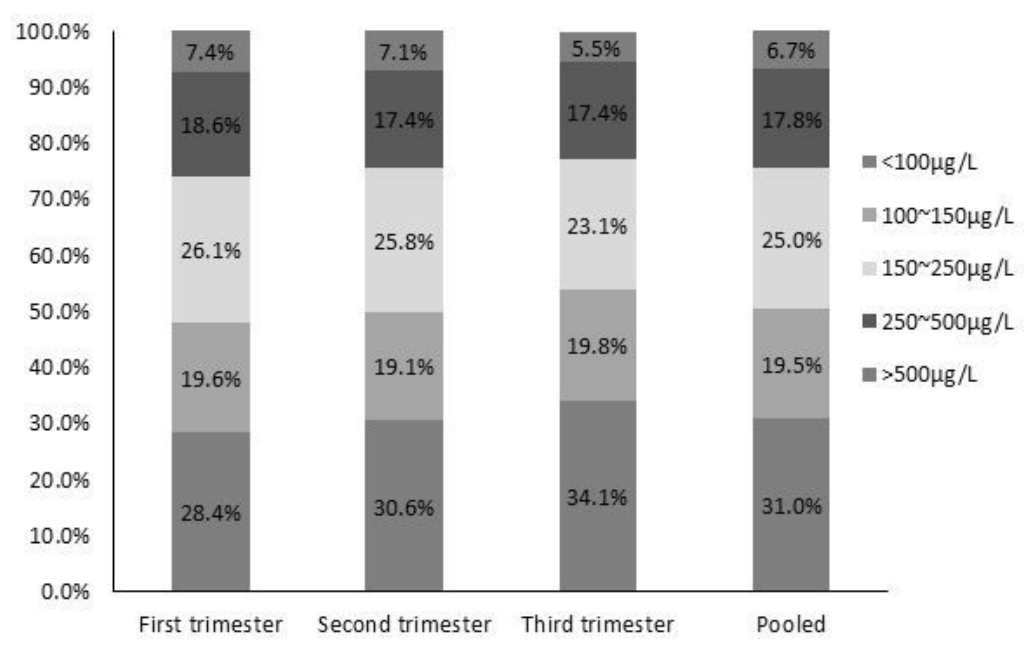

\section{Figure 1}

Proportion of urinary iodine concentrations in pregnant women (\%). 


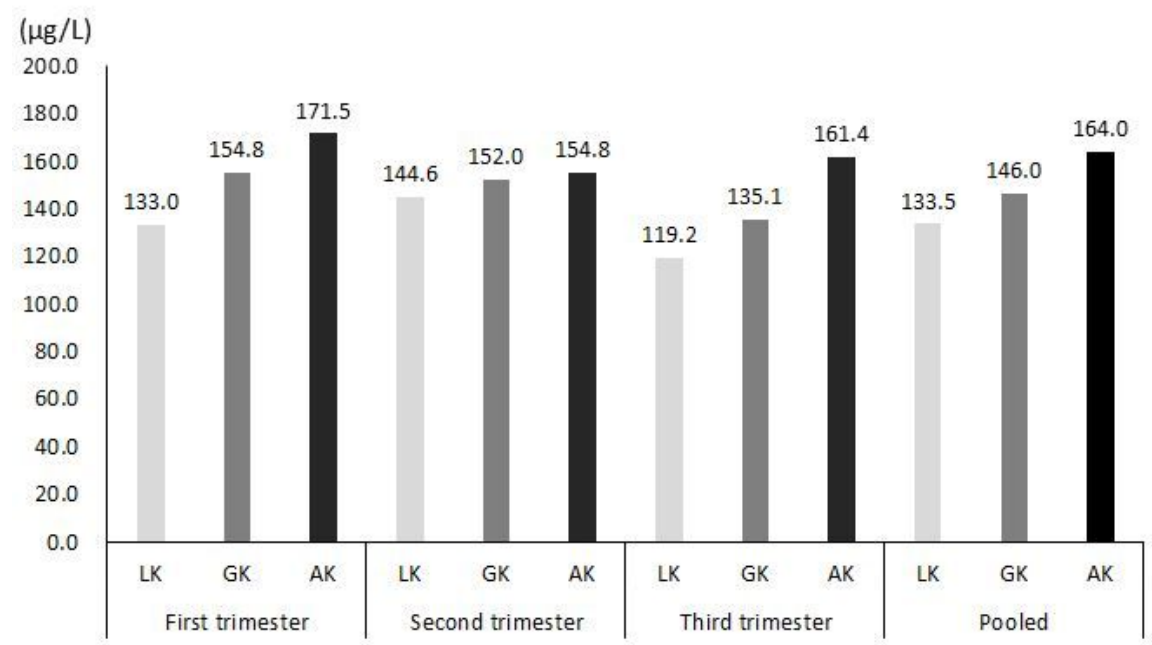

Figure 2

Distribution of urinary iodine status by the total knowledge scores of the participants. $(\mathrm{LK}=$ lack of knowledge, GK = general knowledge, and $\mathrm{AK}=\mathrm{abundant}$ knowledge) 